\title{
Analysis of Risk Factors for Recurrence of Benign Paroxysmal Positional Vertigo: An II-Year Nationwide Population-Based Study
}

\author{
Su-Jin $\mathrm{Han}^{1 *}$, Chang Yong Kim ${ }^{1 \dagger}$, Dae Bo Shim ${ }^{2}$, and Mee Hyun Song ${ }^{2}$ \\ ${ }^{1}$ Department of Otorhinolaryngology-Head and Neck Surgery, National Health Insurance Service Ilsan Hospital, Goyang; and \\ ${ }^{2}$ Department of Otorhinolaryngology-Head and Neck Surgery, Myongji Hospital, Hanyang University College of Medicine, \\ Goyang, Korea
}

\author{
양성 돌발두위현훈의 재발 요인 분석: 11 년간의 국민건강보험공단 표본 코호트 연구 \\ 한수진 $^{1 *} \cdot$ 김창용 $^{1 \dagger} \cdot$ 심대보 ${ }^{2} \cdot$ 송미현 ${ }^{2}$ \\ 국민건강보험 일산병원 이비인후과, ${ }^{1}$ 한양대학교 의과대학 명지병원 이비인후과 ${ }^{2}$
}

\author{
Received September 19, 2017 \\ Revised January 4, 2018 \\ Accepted January 18, 2018 \\ Address for correspondence \\ Mee Hyun Song, MD, PhD \\ Department of Otorhinolaryngology- \\ Head and Neck Surgery, \\ Myongji Hospital, \\ Hanyang University \\ College of Medicine \\ 55 Hwasu-ro 14beon-gil, \\ Deogyang-gu, Goyang 10475, Korea \\ Tel +82-31-810-5406 \\ Fax +82-31-969-0500 \\ E-mail meehyun924@hanmail.net \\ *Current address: Soree Ear Clinic \\ ${ }^{\dagger}$ Current address: Gochang Hospital
}

Background and Objectives Benign paroxysmal positional vertigo (BPPV) is one of the most common causes of dizziness with a high recurrence rate. This study aimed to analyze the recurrence rate and the risk factors for recurrence using the Korean National Health Insurance Service National Sample Cohort (NHIS-NSC 2002-2013) data.

Subjects and Method Patients aged 20 years or older who were diagnosed with BPPV in the period of 2002-2012 and had at least 1 year of monitoring period were included in this study. The diagnosis of BPPV was made when the code for BPPV (KCD-6 code H811) was used or when canalith reposition therapy (EDI code MX035) was entered even in cases with different diagnoses. The risk factors of BPPV recurrence were analyzed.

Results Of the total of 21355 patients diagnosed with BPPV, 5876 patients (28\%) demonstrated recurrence. Multiple recurrences were common. When using the univariate regression analysis, age, sex, vestibular disease, headache, osteoporosis, and ischemic heart disease were found significant. When the patients were classified into 4 groups according to age and sex, vestibular diseases were found as a common risk factor for recurrence in all groups, while headache, osteoporosis, hypertension, and ischemic heart disease were significant in females.

Conclusion The recurrence rate of BPPV in the Korean adult population was approximately $28 \%$ and recurrences were more common in patients aged over 65 and in females. Patients with vestibular diseases were at a higher risk of recurrence regardless of age or sex, while headache, osteoporosis, hypertension and ischemic heart disease increased the risk of recurrence in females.

Korean J Otorhinolaryngol-Head Neck Surg 2019;62(1):15-22

Key Words Benign paroxysmal positional vertigo $\cdot$ Cohort $\cdot$ Recurrence $\cdot$ Risk factors.

\section{서 론}

양성돌발두위현훈(benign paroxysmal positional vertigo,

This is an Open Access article distributed under the terms of the Creative Commons Attribution Non-Commercial License (https://creativecommons.org/licenses/by-nc/4.0) which permits unrestricted non-commercial use, distribution, and reproduction in any medium, provided the original work is properly cited.
$\mathrm{BPPV})$ 은 말초성 현훈의 가장 흔한 원인으로 두위 변화에 의 해 짧은 회전성 어지럼이 반복적으로 나타나고 특정 자세에 서 특징적인 안진이 관찰되면 진단이 가능하다. ${ }^{1)} \mathrm{BPPV}$ 는 약 50 70\%에서 특발성으로 발생하지만, 내이 손상을 유발하는 여러 원인에 의해 이차적으로 유발될 수 있다. ${ }^{2)}$ 알려진 이차 적 원인으로는 머리 외상이 가장 흔하며, 그 외 전정신경염, 미 
로염, 메니에르병과 같은 내이질환과 두통 등이 있다. ${ }^{3)} \mathrm{BPPV}$ 의 치료는 이석정복술이 권장되고 있고, 발생한 반고리관에 따라 Epley 수기, Semont 수기, 바비큐 회전 수기, Gufoni 수 기, 팽대부마루 이석정복술(cupulolith repositioning maneuver) 등 다양한 방법이 개발되어 있다.,4) $\mathrm{BPPV}$ 의 치료로 서 이석정 복술의 치료 효과는 대략 60 90\% 정도로 비교적 높은 편이다. 그러나 $\mathrm{BPPV}$ 의 재발률 역시 높아 경과 관찰 기간에 따라 차이가 있지만 약 15 50\% 정도에서 재발하는 것으로 보고되고 있다. ${ }^{1,3,-7)}$

BPPV 재발의 위험인자로는 연구에 따라 차이를 보이는데 성별, 나이, 증상의 기간이나 유발 원인 등이 $\mathrm{BPPV}$ 의 재발 과 연관이 없다는 보고도 있는 반면 여성, 골다공증, 내림프 수종이 동반된 경우, 두 가지 이상의 전신적인 동반 질환이 있 는 경우, 처음 발병 당시 여러 번의 이석정복술이 시행된 경우 등에서 $\mathrm{BPPV}$ 의 재발 위험성이 높아진다는 결과도 제시된 바 있다. ${ }^{37-12)}$ 이에 본 저자들은 국민건강보험 공단 표본 코호 트 자료를 이용하여 $\mathrm{BPPV}$ 의 재발 및 그 양상을 분석하고 $\mathrm{BPPV}$ 재발의 위험인자를 확인하고자 하였다.

\section{대상 및 방법}

본 연구는 국민건강 보험공단 표본 코호트[Korean National Health Insurance Service(NHIS) National Sample Cohort 2002 2013] 자료를 이용하였고, 이는 국민건강보험 공단의 윤 리위원회로 부터 승인된 자료(NHIS-2016-2-253)이며, 연구의 진행은 보험공단 일산병원 윤리위원회의 심의(NHIMC 201601-024)를 받은 후 이루어졌다.

\section{연구 데이터 베이스}

2013년을 기준으로 하였을 때 우리나라 국민 51448491명 (남자: 25780383명, 여자: 25668348명) 중 97.1\%가 건강보험 제도에 가입되어 있는데, 본 연구는 이 중 약 $2 \%$ 에 해당하는 1025340 명을 표본으로 추출한 국민건강보험 공단 표본 코호 트(NHIS-NSC 2002-2013) 자료를 이용하여 이 자료에 포함 된 외래진료 기록과 약국 청구자료를 참고하여 분석하였 다. ${ }^{13)}$ 표본 코호트 자료의 진단명은 국제질병분류(ICD-10)를 수정한 한국표준질병사인분류(KCD-6)에 기초하고 있다.

\section{대 상}

2002년부터 2012년까지의 기간 동안 20세 이상의 성인을 대 상으로 최소 1년 이상의 추적 관찰 기간을 확보하여 연구를 진행하였다. $\mathrm{BPPV}$ 환자의 정의는 국내 이비인후과 병원에서 양성발작성두위현훈 $(\mathrm{KCD}-6 \mathrm{H} 811)$ 의 진단명이 발생하였거
나 타 진단명인 경우에도 이석정복술(EDI code MX035)을 시 행 받은 경우로 정의하였다.

$\mathrm{BPPV}$ 의 재발은 양성돌발두위현훈(H811)의 진단명이나 이석정복술(MX035)이 최초 진단 시점부터 최소 1개월 이상 없어졌다가 다시 발생한 경우로 정의하였다. 상기 진단명이나 처치가 1 개월 이상의 공백기를 가지지 않고 계속 발생한 경 우는 제외하였다.

\section{방 법}

$\mathrm{BPPV}$ 의 재발에 연령이 영향을 미치는지 분석하였고, 기준 으로 한 연령은 정부에서 정한 노인의 연령 기준이며 기존 여러 연구에서 기준 연령으로 사용한 65 세를 기준으로 65 세 이상 과 65세 미만의 두 군으로 나누어 분석하였다. ${ }^{11,12,14)} \mathrm{BPPV}$ 의 재발요인으로 고려할 수 있는 동반 질환으로는 당뇨(E10.014.9), 고혈압(I10-13, I15-I15), 골다공증(M80-82)을 진단받 고 그 치료약제를 복용하고 있는 경우와 그 외 신장질환(N18), 허혈성 심장질환(I20-25), 뇌혈관질환(I60-67), 두통(R51, G4344), 결합조직 침범 자가면역질환(M30-36, M05-09, M45)을 분석하였으며, 상기 진단명이 $\mathrm{BPPV}$ 의 진단 전에 발생한 경우 만을 포함하여 분석하였다. $\mathrm{BPPV}$ 의 재발에 영향을 줄 수 있 는 두부외상(S02, S06, S07)이나 전정기능 장애(H80, H81.0, H81.2, H83.0, H83.2)는 BPPV의 진단 이전 6개월 이내에 발 생한 경우로 제한하였다. 또한, 유양동삭개술(S5671, S5672), 등골수술(S5690, S5695), 이소골재건술(S5791)과 같은 이과 수 술이 BPPV의 진단 이전 6개월 이내에 시행된 경우도 분석하 였다. 상기 요인들이 재발의 위험인자로 작용하는지 확인하기 위하여, 상기 요인들이 동반되는 경우와 상기 요인들이 없는 대조군을 비교하여 $\mathrm{BPPV}$ 의 재발률에 차이가 있는지를 확인 하였다.

\section{통 계}

재발 요인이 없는 대조군에 비교하여 재발 요인이 있는 군에 서 BPPV가 1회 발생한 경우와 2회 이상 발생한 경우 사이의 차이를 확인하고, 각 연령대에 발생한 전체 $\mathrm{BPPV}$ 환자 중 재 발한 환자 비율이 연령대별로 의미 있는 차이가 있는지 확인 하기 위해 chi-square 분석을 이용하였다.

연령과 성별에 따른 재발률의 차이를 분석하기 위하여 여러 질환이 같이 이환되어 있는 특성을 보정한 다변량 $\operatorname{Cox}$ 비례 위험모형(multivariate Cox proportional hazard regression) 을 사용하였다. 모든 분석에서 $p$ 값이 0.05 미만인 경우를 통 계학적으로 유의한 것으로 하였으며, 통계 패키지는 윈도우 용 SAS 9.4 version(SAS Inc., Cary, NC, USA)을 이용하였다. 


\section{결 과}

본 연구에서 정의된 BPPV 환자 총 21355명 중 남자가 6383 명, 여자가 14972명으로 여성이 남성보다 2.3배 많았으며, 평 균 연령은 $54.4 \pm 15.5$ 세였다. 이 중 BPPV가 재발한 환자는 총 5876 명으로 전체 $\mathrm{BPPV}$ 환자의 $28 \%$ 에 해당되었다. 환자들 이 추적 관찰된 기간은 평균 $48.2 \pm 37.2$ 개월로, 상기 기간 동안 3 회와 4회 재발한 경우가 각각 $43 \%$ 와 $25 \%$ 로 가장 많았고, 5 회 재발률이 $13 \%, 6$ 회 재발률이 $7 \%$ 로 확인되었다. 재발한 환자 5876명 중에 $\mathrm{BPPV}$ 의 초기 진단 후 12 개월 이내에 재발 한 경우가 3373 명으로 재발한 전체 환자의 $57 \%$ 에 해당하였 으며, 24개월 이내에 재발한 경우는 4348명으로 재발한 전체 환자의 $74 \%$ 를 차지하였다(Fig. 1). BPPV가 한 번만 발생한 경우와 재발한 경우를 모두 포함하여 전체 발생률을 연령별 로 분석해보면, 40 대 이후에 $\mathrm{BPPV}$ 의 전체 발생률이 증가하 여 BPPV가 발생한 총 연구 대상자 21355 명 중 40 대에 발생 한 경우가 4205명(20\%), 50대에 발생한 경우가 4838명(23\%), 그리고 60대에 발생한 경우가 4276명(20\%)이었다(Fig. 2). 초 회 진단 연령대별로 재발률을 비교해보면 통계적으로 유의하 게 재발률에 차이가 있었으며 $(p<0.001), 50$ 대 이상에서는 각 연령대에 발생한 전체 $\mathrm{BPPV}$ 환자 중 재발한 환자 비율이 약 30 35\%로 20대나 30대에 비하여 높게 나타났다(Fig. 2).

$\mathrm{BPPV}$ 의 재발요인으로 고려할 수 있는 인자들에 대하여 $\mathrm{BPPV}$ 의 재발률에 영향을 미치는지 단변량 분석을 시행하였을 때, $\mathrm{BPPV}$ 의 재발 위험성이 전정 질환이 동반되는 경우 $34 \%$, 65세 이상에서 $31 \%$, 두통이 동반되는 경우 $15 \%$, 허혈성 심장 질환이 동반되는 경우와 여성의 경우 각각 $10 \%$, 고혈압과 골 다공증이 있는 경우 각각 $8 \%$ 증가하였다(Table 1).

성별과 연령 요인을 배제하고 다른 질환에 의한 재발의 증 가 여부를 분석하기 위하여, 65세를 기준으로 남녀 성별에 따

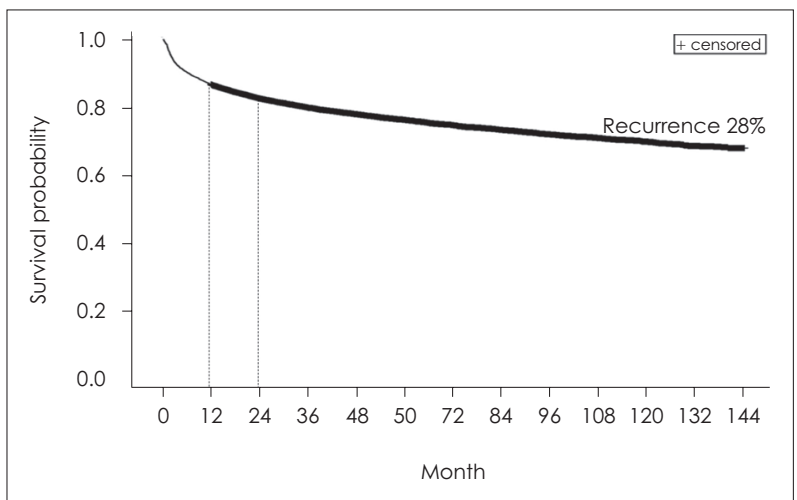

Fig. 1. The Kaplan-Meier estimation for recurrence of BPPV. The recurrence rate was $28 \%$. Of the patients with BPPV recurrence, $57 \%$ and $74 \%$ recurred within 12 months and 24 months of initial diagnosis (vertical dashed lines), respectively. BPPV: benign paroxysmal positional vertigo.
라 4개의 군으로 나누어 재발 요인을 분석하였다. 65 세 이상 남자의 경우, 총 1820명 중 594명(33\%)에서 재발하였고, 전 정 질환이 동반되는 경우 $\mathrm{BPPV}$ 재발의 위험이 $62 \%$ 증가하 였으나 다른 동반 질환은 통계학적으로 의미가 없었다(Table 2). 65세 미만 남자의 경우, 총 4563명 중 재발한 환자는 995 명으로 전체의 약 $22 \%$ 에 해당하였고 역시 이 경우에도 전정 질환이 동반되면 $\mathrm{BPPV}$ 의 재발 위험이 약 $38 \%$ 증가하였다 (Table 2). 65세 이상 여자의 경우, 4049 명 중 전체의 $35 \%$ 인 1403 명에서 재발하였고 $\mathrm{BPPV}$ 의 재발 위험성은 전정 질환이 동반될 경우 $33 \%$, 허혈성 심장질환이 동반될 경우 $19 \%$ 증가 하였다(Table 3). 65세 미만 여자의 경우, 총 10923명 중 26\% 인 2884명에서 재발하였고, $\mathrm{BPPV}$ 의 재발 위험성은 전정 질 환이 동반될 경우 $29 \%$, 두통이 동반될 경우 $20 \%$, 고혈압이 동반될 경우 $19 \%$, 그리고 골다공증이 동반될 경우 $17 \%$ 증가 하였다(Table 3).

\section{고 찰}

$\mathrm{BPPV}$ 는 전체 어지럼증 환자의 약 $20 \%$ 를 차지할 정도로 매우 흔한 질환으로 그 유병률은 계속 증가하고 있으며, 이는 $\mathrm{BPPV}$ 진단의 정확도 향상과 더불어 사회의 고령화와 연관 이 있을 것으로 생각된다. ${ }^{11)} \mathrm{BPPV}$ 의 재발에 대한 기존 연구 들에서는 여러 위험인자가 재발률에 미치는 영향에 대하여 다양한 결과를 보이는데, 동일한 위험인자에 대하여 상반된 결과를 보이기도 한다.,7-12) 따라서 이러한 재발의 위험인자를 확인하기 위해 본 연구에서는 대단위의 코호트 자료를 이용하

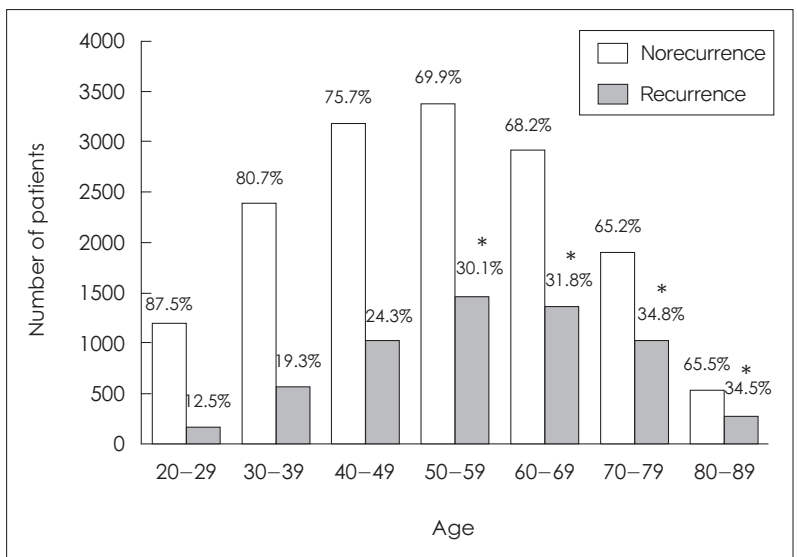

Fig. 2. Distribution of age at initial diagnosis of benign paroxysmal positional vertigo in cases with or without recurrences. The proportion of recurrent cases within each age group rose above $30 \%$ for patients above and including the 6 th decade. The numbers marked on the top of each bar represent the percentage of cases with or without recurrences within each age group. The percentage was marked with an asterisk $(*)$ when it was above $30 \%$. The difference of recurrence rates among the age groups was statistically significant $\left(\chi^{2}=431.866, \mathrm{df}=6, p<0.001\right)$. 
여 국내에서의 BPPV 유병률과 재발률을 분석하고자 하였다. 우선 본 연구에서 BPPV의 발생 양상을 보면, 50 60대에 서 발생률이 가장 높고 여성에서 남성에 비하여 2.3배 발생률 이 높아 기존에 보고된 연구 결과와 비슷한 양상을 보였다. ${ }^{2}$ 장기 재발률에 대한 연구들을 살펴보면, Brandt 등)은 125 명 의 $\mathrm{BPPV}$ 환자를 10 년간 추적 관찰하였을 때, 재발률이 $50 \%$
이고 재발한 환자 중 $80 \%$ 가 1 년 이내에 재발하였다고 보고 하였다. 그러나, 추적 관찰 기간이 4 6년 사이인 연구들은 재 발률이 25 40\%로 보고하였으며, 이는 본 연구에서의 재발률 $28 \%$ 와 비슷한 결과를 보였다. ${ }^{3,10,15)}$

본 연구에서 단변량 분석을 시행하였을 때 연령과 성별에 따라 재발률에 의미 있는 차이를 보였고 그 외에 전정 질환,

Table 1. Univariate Cox regression analyses of the overall HR related to the recurrence of benign paroxysmal positional vertigo over an eleven-year follow-up period

\begin{tabular}{|c|c|c|c|c|}
\hline \multirow{2}{*}{ Variable } & No recurrence & Recurrence & \multirow{2}{*}{$\mathrm{HR}(95 \% \mathrm{Cl})$} & \multirow{2}{*}{ p-value } \\
\hline & $\mathrm{n}(\%)$ & $n(\%)$ & & \\
\hline Gender & & & & $0.001^{*}$ \\
\hline Male & $4794(75.1)$ & $1589(24.9)$ & $0.904(0.850-0.960)$ & \\
\hline Female & $10685(71.4)$ & $4287(28.6)$ & 1 & \\
\hline Age & & & & $<0.001^{*}$ \\
\hline$\geq 65$ years & $3872(66.0)$ & $1997(34.0)$ & $1.312(1.232-1.397)$ & \\
\hline$<65$ years & $11607(75.0)$ & $3879(25.0)$ & 1 & \\
\hline Hypertension & & & & $0.019^{*}$ \\
\hline Yes & $4820(69.3)$ & $2135(30.7)$ & $1.079(1.013-1.150)$ & \\
\hline No & $10659(74.0)$ & $3741(26.0)$ & 1 & \\
\hline Diabetes mellitus & & & & 0.874 \\
\hline Yes & $1219(70.6)$ & $508(29.4)$ & $0.992(0.902-1.091)$ & \\
\hline No & $14260(72.7)$ & $5368(27.3)$ & 1 & \\
\hline Osteoporosis & & & & $0.021^{*}$ \\
\hline Yes & $2539(67.2)$ & $1239(32.8)$ & $1.086(1.012-1.165)$ & \\
\hline No & $12940(99.8)$ & $4637(0.2)$ & 1 & \\
\hline Chronic renal disease & & & & 0.160 \\
\hline Yes & $100(74.6)$ & $34(25.4)$ & $1.276(0.908-1.792)$ & \\
\hline No & $15379(72.5)$ & $5842(27.5)$ & 1 & \\
\hline Ischemic heart disease & & & & $0.016^{*}$ \\
\hline Yes & $1933(68.6)$ & $885(31.4)$ & $1.099(1.018-1.186)$ & \\
\hline No & $13546(73.1)$ & $4991(26.9)$ & 1 & \\
\hline Stroke & & & & 0.880 \\
\hline Yes & $2165(69.3)$ & $961(30.7)$ & $1.006(0.934-1.083)$ & \\
\hline No & $13314(73.0)$ & $4915(27.0)$ & 1 & \\
\hline Head trauma & & & & 0.374 \\
\hline Yes & $256(75.7)$ & $82(24.3)$ & $1.104(0.888-1.373)$ & \\
\hline No & $15223(72.4)$ & $5794(27.6)$ & 1 & \\
\hline Ear surgery & & & & 0.156 \\
\hline Yes & $49(66.2)$ & $25(33.8)$ & $0.753(0.508 \sim 1.115)$ & \\
\hline No & $15430(72.5)$ & $5851(27.5)$ & 1 & \\
\hline Vestibular disease & & & & $<0.001^{*}$ \\
\hline Yes & $2944(67.1)$ & $1445(32.9)$ & $1.344(1.266-1.427)$ & \\
\hline No & $12535(73.9)$ & $4431(26.1)$ & 1 & \\
\hline Headache & & & & $<0.001^{*}$ \\
\hline Yes & $7330(70.8)$ & $3017(29.2)$ & $1.155(1.096-1.217)$ & \\
\hline No & $8149(74.0)$ & $2859(26.0)$ & 1 & \\
\hline Autoimmune disease & & & & 0.120 \\
\hline Yes & $2139(69.6)$ & $933(30.4)$ & $1.059(0.985-1.139)$ & \\
\hline No & $13340(73.0)$ & $4943(27.0)$ & 1 & \\
\hline
\end{tabular}


두통, 허혈성 심장질환, 고혈압, 그리고 골다공증이 통계적으 로 유의한 인자들로 분석되었다. 연령의 경우 65 세 이상일 때 가 65세 미만일 때보다 재발의 위험이 약 $31 \%$ 증가하는 것으 로 분석되었는데, 연령에 따른 $\mathrm{BPPV}$ 의 재발 증가 요인으로는 노화에 따른 칼슘대사의 변화로 인한 칼슘 농도 저하와 이석 농도의 감소, 이석막의 퇴화, 미세혈관 장애로 인한 허혈 등 이 연관이 있을 것으로 추정되고 있다. ${ }^{16)}$ 또한, 동물실험에 의하면 연령이 증가할수록 이석의 형태가 갈라지고 조각나게 되며 연결 섬유들도 약해지는 것으로 확인되었다. ${ }^{17)}$ 기존의 연구들에서 성별에 의한 재발률의 영향에 대해 상반된 연구 결과를 보이나, 다수의 연구들이 여성에서 $\mathrm{BPPV}$ 의 발생률
과 재발률이 더 높다고 보고하고 있는데, 이는 여성에서의 호르몬 변화와 연관성이 높을 것으로 추정된다. $37,8,14,18)$ 특히 많은 연구가 폐경기 여성에서 BPPV의 발생 및 재발률이 높 은 것은 골밀도 감소와 같은 신체 대사의 변화 뿐만 아니라 여성 호르몬의 변동에 따른 심리적인 변화도 영향을 줄 수 있다고 보고하고 있다..$^{14,18-21)}$

성별과 연령에 따라 4 개의 군으로 나누어 다변량 분석을 하 였을 때, 남성에서는 65세 이상일 때와 65세 미만일 때 모두 전정 질환만이 의미 있는 재발 인자로 분석되었고 여성의 경우 65세 이상에서는 전정 질환과 허혈성 심장질환, 65 세 미만에 서는 전정질환, 두통, 골다공증, 고혈압이 의미 있는 인자로

Table 2. Multivariate Cox regression analyses of overall HR related to the recurrence of BPPV in males

\begin{tabular}{|c|c|c|c|c|c|c|}
\hline \multirow{2}{*}{ Variable } & \multicolumn{2}{|r|}{$\geq 65$ years } & \multirow{2}{*}{ p-value } & \multicolumn{2}{|r|}{$<65$ years } & \multirow{2}{*}{$p$-value } \\
\hline & $n$ & $\mathrm{HR}(95 \% \mathrm{Cl})$ & & $n$ & $\mathrm{HR}(95 \% \mathrm{Cl})$ & \\
\hline Hypertension & & & 0.360 & & & 0.128 \\
\hline Yes & 1148 & $0.920(0.769-1.100)$ & & 1146 & $1.126(0.966-1.313)$ & \\
\hline No & 672 & 1 & & 3417 & 1 & \\
\hline Diabetes Mellitus & & & 0.542 & & & 0.424 \\
\hline Yes & 345 & $0.936(0.756-1.158)$ & & 306 & $0.903(0.702-1.160)$ & \\
\hline No & 1475 & 1 & & 4257 & 1 & \\
\hline Osteoporosis & & & 0.542 & & & 0.681 \\
\hline Yes & 151 & $0.909(0.669-1.235)$ & & 56 & $0.882(0.486-1.602)$ & \\
\hline No & 1669 & 1 & & 4507 & 1 & \\
\hline Chronic renal disease & & & 0.490 & & & 0.466 \\
\hline Yes & 32 & $1.266(0.648-2.475)$ & & 25 & $1.445(0.537-3.884)$ & \\
\hline No & 1788 & 1 & & 4538 & 1 & \\
\hline Ischemic heart disease & & & 0.062 & & & 0.846 \\
\hline Yes & 483 & $1.199(0.991-1.452)$ & & 484 & $0.979(0.794-1.208)$ & \\
\hline No & 1337 & 1 & & 4079 & 1 & \\
\hline Stroke & & & 0.978 & & & 0.353 \\
\hline Yes & 594 & $0.998(0.833-1.194)$ & & 474 & $0.904(0.731-1.118)$ & \\
\hline No & 1226 & 1 & & 4089 & 1 & \\
\hline Head trauma & & & 0.066 & & & 0.603 \\
\hline Yes & 47 & $1.925(0.957-3.871)$ & & 92 & $0.889(0.570-1.386)$ & \\
\hline No & 1773 & 1 & & 4471 & 1 & \\
\hline Ear surgery & & & 0.952 & & & $0.048^{*}$ \\
\hline Yes & 5 & $-\dagger$ & & 21 & $0.495(0.247-0.993)$ & \\
\hline No & 1815 & & & 4542 & 1 & \\
\hline Vestibular disease & & & $<0.001^{*}$ & & & $<0.001^{*}$ \\
\hline Yes & 360 & $1.622(1.346-1.954)$ & & 855 & $1.378(1.189-1.596)$ & \\
\hline No & 1460 & 1 & & 3708 & 1 & \\
\hline Headache & & & 0.384 & & & 0.055 \\
\hline Yes & 801 & $1.076(0.912-1.270)$ & & 1725 & $1.135(0.997-1.292)$ & \\
\hline No & 1019 & 1 & & 2838 & 1 & \\
\hline Autoimmune disease & & & 0.345 & & & 0.675 \\
\hline Yes & 281 & $1.113(0.891-1.391)$ & & 319 & $1.053(0.826-1.344)$ & \\
\hline No & 1539 & 1 & & 4244 & 1 & \\
\hline
\end{tabular}


분석되었다. 모든 군에서 공통적으로 전정 질환이 재발 인자 로 나타났는데, 기존 연구들도 전정신경염, 돌발성 난청, 메니 에르병 등의 내이질환의 과거력이 있는 경우 재발률이 증가 한다고 보고하고 있다. ${ }^{11,12,22)}$ 고혈압이나 허혈성 심장질환이 동반되는 경우에도 $\mathrm{BPPV}$ 의 재발률이 증가하였는데 이러 한 전신 질환은 내이의 허혈성 손상을 초래하여 이석막으로부 터 이석의 탈락을 유발하는 것으로 생각된다. ${ }^{914)}$

두통이 동반되는 경우, $\mathrm{BPPV}$ 는 미로 동맥의 혈관 경련에 의한 이석의 탈락으로 발생할 수 있다. ${ }^{23)} \mathrm{BPPV}$ 가 두통과 동 반되는 경우 이석의 비정상적 흥분 신호로 인한 감각 자극의 변화 때문에 두통이 발생한다고 생각할 수도 있으나, 혈관 경
련으로 인한 내이의 손상이 전정 상피세포의 손상을 초래하 여 이석이 탈락할 수 있다. ${ }^{14,23)}$ 또한 편두통 동물 실험 모델에 의하면 반복되는 신경성 염증이 이석기관의 손상을 초래하 는 것으로 관찰되어 이 또한 두통과 동반된 $\mathrm{BPPV}$ 의 발생 기 전으로 생각될 수 있겠다. ${ }^{24)}$ 본 연구 결과에서도 두통이 동반 되는 경우 전체 환자의 $15 \%, 65$ 세 미만 여성에서는 약 $20 \%$ 에서 $\mathrm{BPPV}$ 의 재발률이 증가하였다.

골다공증이 동반되는 경우 재발의 위험이 전체 $\mathrm{BPPV}$ 환 자에서는 $9 \%, 65$ 세 미만 젊은 여성에서는 $17 \%$ 증가하였는데, 기존 연구에 따르면 $\mathrm{BPPV}$ 환자에서 골밀도가 정상인보다 감소하여 있고 골다공증이 동반된 $\mathrm{BPPV}$ 환자의 경우 재발

Table 3. Multivariate Cox regression analyses of overall HR related to the recurrence of benign paroxysmal positional vertigo in females

\begin{tabular}{|c|c|c|c|c|c|c|}
\hline \multirow{2}{*}{ Variable } & \multicolumn{2}{|c|}{$\geq 65$ years } & \multirow{2}{*}{$p$-value } & \multicolumn{2}{|r|}{$<65$ years } & \multirow{2}{*}{ p-value } \\
\hline & $n$ & $\mathrm{HR}(95 \% \mathrm{Cl})$ & & $n$ & $\mathrm{HR}(95 \% \mathrm{Cl})$ & \\
\hline Hypertension & & & 0.839 & & & $<0.001^{*}$ \\
\hline Yes & 2615 & $0.988(0.880-1.109)$ & & 2046 & $1.194(1.083-1.316)$ & \\
\hline No & 1434 & 1 & & 8877 & 1 & \\
\hline Diabetes Mellitus & & & 0.627 & & & 0.167 \\
\hline Yes & 655 & $0.964(0.833-1.117)$ & & 421 & $1.151(0.943-1.405)$ & \\
\hline No & 3394 & 1 & & 10502 & 1 & \\
\hline Osteoporosis & & & 0.149 & & & $0.002 *$ \\
\hline Yes & 1998 & $1.083(0.972-1.206)$ & & 1573 & $1.172(1.059-1.296)$ & \\
\hline No & 2051 & 1 & & 9350 & 1 & \\
\hline Chronic renal disease & & & 0.062 & & & 0.339 \\
\hline Yes & 47 & $1.815(0.972-3.392)$ & & 30 & $0.748(0.412-1.356)$ & \\
\hline No & 4002 & 1 & & 10893 & 1 & \\
\hline Ischemic heart disease & & & $0.006^{*}$ & & & 0.706 \\
\hline Yes & 972 & $1.193(1.053-1.352)$ & & 879 & $1.026(0.896-1.176)$ & \\
\hline No & 3077 & 1 & & 10044 & 1 & \\
\hline Stroke & & & 0.875 & & & 0.306 \\
\hline Yes & 1167 & $1.010(0.895-1.139)$ & & 891 & $1.071(0.939-1.220)$ & \\
\hline No & 2882 & 1 & & 10032 & 1 & \\
\hline Head trauma & & & 0.616 & & & 0.901 \\
\hline Yes & 63 & $1.127(0.707-1.794)$ & & 136 & $1.021(0.735-1.419)$ & \\
\hline No & 3986 & 1 & & 10787 & 1 & \\
\hline Ear surgery & & & 0.333 & & & 0.600 \\
\hline Yes & 14 & $0.693(0.329-1.457)$ & & 34 & $0.847(0.455-1.576)$ & \\
\hline No & 4035 & 1 & & 10889 & 1 & \\
\hline Vestibular disease & & & $<0.001^{*}$ & & & $<0.001^{*}$ \\
\hline Yes & 890 & $1.333(1.182-1.505)$ & & 2284 & $1.292(1.186-1.407)$ & \\
\hline No & 3159 & 1 & & 8639 & 1 & \\
\hline Headache & & & 0.065 & & & $<0.001^{*}$ \\
\hline Yes & 2315 & $1.108(0.994-1.234)$ & & 5506 & $1.200(1.114-1.293)$ & \\
\hline No & 1734 & 1 & & 5417 & 1 & \\
\hline Autoimmune disease & & & 0.672 & & & 0.233 \\
\hline Yes & 997 & $1.027(0.908-1.162)$ & & 1475 & $1.067(0.959-1.186)$ & \\
\hline No & 3052 & 1 & & 9448 & 1 & \\
\hline
\end{tabular}


의 위험성이 유의하게 높다고 보고하고 있다. ${ }^{25)}$ Yamanaka 등 ${ }^{20)}$ 은 골다공증이 있는 50세 이상의 BPPV 여성 환자 중 $56 \%$ 에서 BPPV가 재발하였고 44\%에서 2회 이상 재발하였다고 보고하였다. 이석은 탄산칼슘으로 이루어져 있는데 이석의 유 지에 중요한 칼슘이온의 흡수가 잘 되지 않거나 골 기질 단백 질로 알려진 osteopontin이 골다공증 환자에서 부족하게 되 면 이석의 형성이 불완전할 수 있다고 한다. ${ }^{20,26)}$ 골다공증은 갱년기 여성에서 에스트로겐의 급격한 감소와 연관이 많은 것 으로 알려져 있으며 이는 칼슘과 골 대사에 중요한 역할을 하 는 에스트로겐의 결핍으로 인하여 이석의 내부 구조에 변형 을 유발하고 이석 간 혹은 이석과 주변 조직 간의 결합에 영향 을 주기 때문일 것으로 생각되고 있다. ${ }^{20,25)}$ 또한, 에스트로겐 결핍으로 인하여 유리 칼슘 이온이 증가하면 분리된 이석 잔 해의 흡수가 떨어져 BPPV의 유발 요인으로 작용할 수 있다. ${ }^{25}$

기존에 알려진 재발요인인 두부외상은 본 연구에서는 통 계 학적 의미가 없었으며, 특히 최근 6개월 이내의 귀 수술 시 행 여부는 BPPV의 재발에 의미가 있을 것으로 의심하였지 만 총 21355명 환자 중 귀 수술을 받은 경우는 모두 74 명으 로 환자 수가 너무 작아 통계학적으로 의의가 나타나지 않은 것으로 생각되었다.

본 연구는 국민건강 보험 공단의 빅데이터를 이용한 연구로 방대한 양의 자료라는 점은 의의가 있지만, 진단명만을 기초 로 한 자료 분석에 따른 한계점이 있을 수 있다. 우선 BPPV로 정의된 환자에서 양성돌발두위현훈(KCD-6 H811)의 특징적 인 안진이 관찰되지 않은 경우 '의증'으로 진단명을 입력한 경 우가 포함되어 있을 수 있다. 이러한 오류를 최대한 줄이기 위 하여 양성돌발두위현훈(KCD-6 H811)이 국내 이비인후과 병 원에서 발생한 경우만을 연구대상으로 하였으며 내과나 신경 과 등 타과의 진단인 경우를 배제하여 최대한 양성돌발두위 현훈 진단의 전문성을 확보하고자 하였다. 반대로 어지럼증 (R42)의 진단명으로 진료가 지속되어 양성돌발두위현훈 (KCD-6 H811)의 진단명이 누락된 경우도 존재할 수 있으므 로 본 연구에서는 이를 보완하기 위해 이석정복술(EDI code $\mathrm{MX035)}$ 을 시행한 환자들을 포함하여 정확성을 높이고자 하 였다. 또한, 진단 코드(KCD-6 H811)나 처치 코드(EDI code $\mathrm{MX035)를} \mathrm{이용하여} \mathrm{정의된} \mathrm{BPPV} \mathrm{환자에서} \mathrm{병의} \mathrm{경과와} \mathrm{예}$ 후에 영향을 줄 수 있는 침범 반고리관의 위치나 향지성 혹은 원지성 아형 여부 등이 재발의 위험인자 분석에 있어서 반영 되지 못한 아쉬움이 있다. 하지만, 실제로 우리나라에서 최근 10 년 동안 이루어진 BPPV의 진단 및 발생 빈도와 재발률을 분석하고 재발과 관련된 동반 질환과의 경향성을 평가한 데 에 그 의의가 있다고 생각된다.

결론적으로 65 세 이상의 고령이거나 여성인 경우, 기저 전정
질환이 동반된 경우 BPPV의 재발 위험성이 높아질 수 있다. 특히 65세 미만의 젊은 여성에서는 두통, 허혈성 심장질환, 고 혈압 및 골다공증이 동반될 때 재발률이 증가한다. 본 연구 결과를 통하여 $\mathrm{BPPV}$ 환자들에게 더욱 정확한 정보의 제공 과 상담이 가능할 것으로 보이며 나아가 이를 바탕으로 한 추가적인 연구를 통하여 $\mathrm{BPPV}$ 의 예방 및 치료에 도움이 될 것으로 생각된다.

\section{Acknowledgments}

This research was supported by the Basic Science Research Program (2015R1A1A1A05001472) of the National Research Foundation (NRF) funded by the Ministry of Science, ICT \& Future Planning.

\section{REFERENCES}

1) Bhattacharyya N, Baugh RF, Orvidas L, Barrs D, Bronston LJ, Cass $\mathrm{S}$, et al. Clinical practice guideline: benign paroxysmal positional vertigo. Otolaryngol Head Neck Surg 2008;139(5 Suppl 4):S47-81.

2) Kim JS, Zee DS. Clinical practice. benign paroxysmal positional vertigo. N Engl J Med 2014;370(12):1138-47.

3) Pérez P, Franco V, Cuesta P, Aldama P, Alvarez MJ, Méndez JC. Recurrence of benign paroxysmal positional vertigo. Otol Neurotol 2012;33(3):437-43.

4) Kim SH, Jo SW, Chung WK, Byeon HK, Lee WS. A cupulolith repositioning maneuver in the treatment of horizontal canal cupulolithiasis. Auris Nasus Larynx 2012;39(2):163-8.

5) Choi SJ, Lee JB, Lim HJ, Park HY, Park K, In SM, et al. Clinical features of recurrent or persistent benign paroxysmal positional vertigo. Otolaryngol Head Neck Surg 2012;147(5):919-24.

6) Simhadri S, Panda N, Raghunathan M. Efficacy of particle repositioning maneuver in BPPV: a prospective study. Am J Otolaryngol 2003;24(6):355-60.

7) Nunez RA, Cass SP, Furman JM. Short- and long-term outcomes of canalith repositioning for benign paroxysmal positional vertigo. Otolaryngol Head Neck Surg 2000;122(5):647-52.

8) Brandt T, Huppert D, Hecht J, Karch C, Strupp M. Benign paroxysmal positioning vertigo: a long-term follow-up (6-17 years) of 125 patients. Acta Otolaryngol 2006;126(2):160-3.

9) De Stefano A, Dispenza F, Suarez H, Perez-Fernandez N, ManriqueHuarte R, Ban JH, et al. A multicenter observational study on the role of comorbidities in the recurrent episodes of benign paroxysmal positional vertigo. Auris Nasus Larynx 2014;41(1):31-6.

10) Sakaida M, Takeuchi $K$, Ishinaga $H$, Adachi M, Majima Y. Longterm outcome of benign paroxysmal positional vertigo. Neurology 2003; 60(9):1532-4.

11) Su P, Liu YC, Lin HC. Risk factors for the recurrence of post-semicircular canal benign paroxysmal positional vertigo after canalith repositioning. J Neurol 2016;263(1):45-51.

12) Tanimoto H, Doi K, Nishikawa T, Nibu K. Risk factors for recurrence of benign paroxysmal positional vertigo. J Otolaryngol Head Neck Surg 2008;37(6):832-5.

13) National Health Insurance Service. National health insurance statistical yearbook. Seoul: Health Insurance Review and Assessment Service and National Health Insurance Service;2014.

14) Picciotti PM, Lucidi D, De Corso E, Meucci D, Sergi B, Paludetti G. Comorbidities and recurrence of benign paroxysmal positional vertigo: personal experience. Int J Audiol 2016;55(5):279-84.

15) Kansu L, Avci S, Yilmaz I, Ozluoglu LN. Long-term follow-up of patients with posterior canal benign paroxysmal positional vertigo. Acta Otolaryngol 2010;130(9):1009-12.

16) Ishiyama G. Imbalance and vertigo: the aging human vestibular periphery. Semin Neurol 2009;29(5):491-9. 
17) Jang YS, Hwang CH, Shin JY, Bae WY, Kim LS. Age-related changes on the morphology of the otoconia. Laryngoscope 2006;116(6):9961001.

18) Ogun OA, Büki B, Cohn ES, Janky KL, Lundberg YW. Menopause and benign paroxysmal positional vertigo. Menopause 2014;21(8): 886-9.

19) Yu S, Liu F, Cheng Z, Wang Q. Association between osteoporosis and benign paroxysmal positional vertigo: a systematic review. BMC Neurol 2014;14:110.

20) Yamanaka T, Shirota S, Sawai Y, Murai T, Fujita N, Hosoi H. Osteoporosis as a risk factor for the recurrence of benign paroxysmal positional vertigo. Laryngoscope 2013;123(11):2813-6.

21) Jang YS, Kang MK. Relationship between bone mineral density and clinical features in women with idiopathic benign paroxysmal positional vertigo. Otol Neurotol 2009;30(1):95-100.

22) Dornhoffer JL, Colvin GB. Benign paroxysmal positional vertigo and canalith repositioning: clinical correlations. Am J Otol 2000; 21(2):230-3

23) Ishiyama A, Jacobson KM, Baloh RW. Migraine and benign positional vertigo. Ann Otol Rhinol Laryngol 2000;109(4):377-80.

24) Vass Z, Steyger PS, Hordichok AJ, Trune DR, Jancsó G, Nuttall AL. Capsaicin stimulation of the cochlea and electric stimulation of the trigeminal ganglion mediate vascular permeability in cochlear and vertebro-basilar arteries: a potential cause of inner ear dysfunction in headache. Neuroscience 2001;103(1):189-201.

25) Jeong SH, Choi SH, Kim JY, Koo JW, Kim HJ, Kim JS. Osteopenia and osteoporosis in idiopathic benign positional vertigo. Neurology 2009;72(12):1069-76.

26) Takemura T, Sakagami M, Nakase T, Kubo T, Kitamura Y, Nomura S. Localization of osteopontin in the otoconial organs of adult rats. Hear Res 1994;79(1-2):99-104. 